\title{
Establishment of an Ecological Security Pattern Under Arid Conditions Based on Ecological Carrying Capacity: a Case Study of Arid Area in Northwest China.
}

\author{
Xiaoyan Cao \\ Lanzhou University \\ Jizong Jiao ( $\sim$ Jiaojz@lzu.edu.cn ) \\ Lanzhou University \\ Xiuli Liu \\ Shanxi University of Finance and Economics \\ Wanyang Zhu \\ Lanzhou University \\ Haoran Wang \\ Lanzhou University
}

\section{Research Article}

Keywords: Ecological carrying capacity, Evolution of space and time, Ecological security pattern, Optimize, Northwest arid region

Posted Date: February 16th, 2022

DOI: https://doi.org/10.21203/rs.3.rs-1267493/v1

License: (c) (i) This work is licensed under a Creative Commons Attribution 4.0 International License.

Read Full License 
Establishment of an ecological security pattern under arid conditions based on ecological carrying capacity: A case study of Arid area in northwest China.

\section{Xiaoyan Cao $^{\text {a }}$ Jizong Jiao $^{\mathrm{a}^{*}}$ Xiuli Liu $^{\mathrm{b}, \mathrm{c}}$ Wanyang Zhu ${ }^{\mathrm{a}}$ Haoran Wanga}

${ }^{a}$ College of Earth and Environmental Sciences, Lanzhou University, Lanzhou 730000, China

${ }^{\mathrm{b}}$ Cooperative Innovation Center for Transition of Resource-based Economics, Shanxi University of Finance \& Economics, Taiyuan 030006, China

${ }^{\mathrm{c}}$ Research Institute of Resource-based Economics, Shanxi University of Finance \& Economics, Taiyuan 030006, China

*Corresponding author. Tel.: +8613669385107. Corresponding Address: College of Earth and Environmental Sciences, Lanzhou

University, Lanzhou 730000, China.;

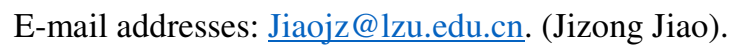

Abstract: With the expansion of the social economy and adjustment of environmental policies, particularly with the onset of development policies for the western region, ecosystems in the arid areas of Northwest China have undergone profound changes. This study collected soil, topographical, climate, and nighttime light data to develop a set of ecological vulnerability assessment indicators based on the background ecological characteristics of the arid areas of Northwest China. The spatiotemporal evolution of ecological carrying capacity were analyzed by our team using Spatial Principal Component Analysis (SPCA) in 2000, 2007, 2012, and 2018 to construct an ecological security pattern. The results revealed that the ecological carrying capacities of the arid areas in the northwest were primarily weak, albeit decreasing, while those areas with strong carrying capacities were increasing. In terms of spatial distribution, the ecological carrying capacities of the Hexi, Northern Xinjiang, and Western Inner Mongolia regions were on the rise, while those of the Southern Xinjiang region were declining. The MCR model was used to extract 51 road-type, river-type, and green corridors with a total length of 7,285.43 km. A total of 71 nodes representing important patch, wet river, and ecologically fragile areas were extracted. According to the calculated results, the arid region of the northwest was divided into 16 ecological security patterns, which were optimized according to changes in their ecological carrying capacities.

Keywords: Ecological carrying capacity; Evolution of space and time; Ecological security pattern; Optimize; Northwest arid region.

\section{Introduction}

With relentlessly increasing demands for natural resources, conflicts between human civilization and the natural environment are becoming increasingly intense ( $\mathrm{Li}$ et al., 2020). The resource carrying capacity of the environment is beyond the limits of 
affordability; thus, investigations into the ecological carrying capacities of different regions has attracted the attention of many ecologists, geographers, and economists. This is particularly the case since the government began to promote the development of ecosystems, wherein the evaluation of their carrying capacities has transitioned from the research to the practical implementation level. It is critical to establish monitoring and early warning mechanisms that are sensitive to the carrying capacity of ecosystems, while implementing restrictive measures on overloaded areas. Through the supervision and evaluation of the overload status of the natural resources of a given region, the diagnosis and prediction of sustainable development lays the foundation for the development of differentiated and operable restrictive measures, which are the basis of regional spatial and overall functional area planning.

Ecological carrying capacities are the most fundamental and critical content for the study of those of resource environments, where the status of ecological carrying capacities directly determines the development and changes in regional resource environment carrying capacities (Chen et al., 2021). Tai-Xia Wu et al (2020). and Filgueira et al (2021). analyzed different aspects of ecological carrying capacities, which are regarded as the self-sustainability of environmental resources to support external socioeconomic pressures. For the arid regions of Northwest China, the application of the ecological carrying capacity concept translates to ensuring sustainable social and economic development, while regulating the rational exploitation and utilization of resources toward the establishment of a virtuous cycle of ecological management (Li et al., 2020).

From the standpoint of research, scholars from different disciplines have conducted in-depth investigations into ecological carrying capacities via state space (Sun et al., 2012), comprehensive evaluation (Wu et al., 2020), ecological footprint (Li et al., 2021), socioecological indicator system (Banos et al., 2014), and other methods (Wei et al., 2020). Ying Li et al (2011) selected 16 indicators from the three dimensions of ecological function elasticity, resource and environment capacity, and socioeconomic coordination to conduct a quantitative evaluation of the ecological carrying capacity of Beijing using the state space method. Jian Peng et al (2016) evaluated the regional ecological carrying capacity of Dali in Yunnan Province from the perspectives of ecological pressure and elasticity based on a comprehensive evaluation carrying capacity model. Further, Xie et al (2011). analyzed the dynamic changes and driving factors of the ecological footprint in the Yellow River Delta. These experts evaluated and analyzed ecological carrying capacities using different research domains. Although this research improves our understanding of regional ecological carrying capacities, several issues remain. For the evaluation of ecological carrying capacities, the statistical spatial interpolation method has been extensively employed to evaluate the impacts of anthropogenic activities on ecosystems. However, in the study of the arid areas of Northwest China, which include sparsely populated areas, the spatial interpolation method does not accurately reflect anthropogenic interference with the ecological environment.

Consequently, for the development of an index system this study took the objectivity of the index into full consideration, and selected nighttime light data as an index for the evaluation of human social pressures (Wei et al.,2021). Nighttime light data has the following advantages in the evaluation of human activities (Wei et al.,2021). Firstly, nighttime light data is suitable for the 
monitoring of human activities over a large area. Secondly, the nighttime light data is not affected by clouds and fog; thus it has strong objectivity. Thirdly, nighttime light data can reflect population (Tan et al., 2018) and economic densities (Jin et al., 2020), the urbanization level (Feng et al., 2020), roads and other information (Zheng et al., 2021), which are highly comprehensive.

The arid regions of Northwest China typically have low ecological carrying capacities in China (Yue et al., 2012). Recently, with changing climatic conditions and multiple anthropogenic interventions, ecosystems in the arid areas of Northwest China have generally become degraded. These aspects include low vegetation coverage, high land degradation index, low biological abundance index, high resource pressure, unreasonable economic structure, and so on. This investigation selected four stages of changes in eco-environmental policies in the study area in 2000 (early stage of western development), 2007 (rapid economic development period), 2012 (early stage of ecological recovery period), and 2018, and selected 13 indicators including topography, hydrology, soil, vegetation, population, and nighttime light index. Spatial principal component analysis (Wei et al., 2019) and the coding method (Wei et al., 2019) were employed to monitor and evaluate the ecological carrying capacities of the arid regions of Northwest China. Thus, to analyze the spatiotemporal variations, those areas with high ecological carrying capacities were selected as ecologically advantaged areas, whereas intersects were chosen as ecological sources; thus, the final ecological resource areas were obtained through their combination with important water sources and forested lands. Based on the minimum cumulative resistance model ( $\mathrm{Li}$ et al., 2015), the arid areas in Northwest China were segmented into 16 ecological security pattern regions, from which three ecological corridors and three ecological nodes were extracted. Based on the variable trends of ecological carrying capacities in the study area, ecological security patterns were designed and optimized to provide suggestions and countermeasures for ecological protection and development.

\section{Study area and data}

\subsection{Study area}

The arid areas of Northwest China (Wei et al., 2020) are bounded by Helan Mountain in the East, and the Kunlun, Altun, and Qilian Mountains in the South, located between $73^{\circ} \mathrm{E}-107^{\circ} \mathrm{E}$ and $35^{\circ} \mathrm{N}-50^{\circ} \mathrm{N}$ (Fig. 1). The administrative region primarily includes the Xinjiang Province, the Hexi Corridor of Gansu Province, and the Western region of Inner Mongolia, which specifically includes 14 locations, prefectures, and cities in Xinjiang, Jiu Quan, Jiayuguan, Zhangye, Wuwei, Jinchang of Gansu Province, and the Alxa League of Inner Mongolia, with an area of $2.09 \times 10^{6} \mathrm{~km}^{2}$ and altitudes ranging from $-154-7311 \mathrm{~m}$. The study area is located deeply inland and far away from the sea, with an annual average precipitation of $\sim<200 \mathrm{~mm}$. The climate is dry, with desert accounting for $64.47 \%$ of the total area, under a typical temperate continental climate. Furthermore, the terrain of the area is undulating and shallow and the ecological environment is very fragile; thus, it is difficult to recover following damage. 

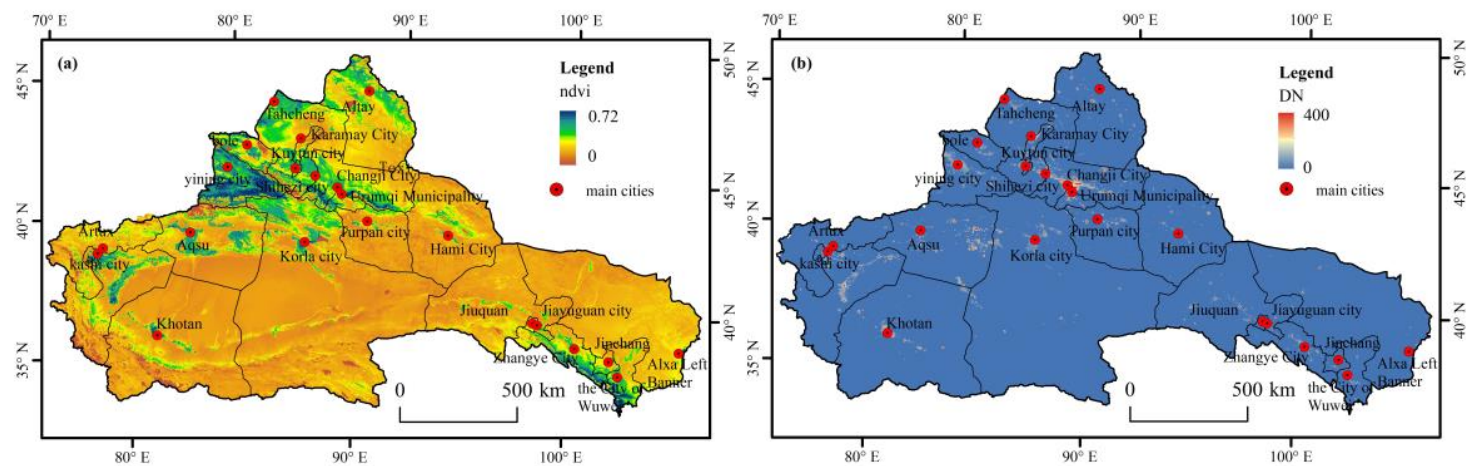

Fig.1 Overview of research area. Note: (a) Normalized difference vegetation index; (b) Nighttime light data.

\subsection{Data resources}

The data used in this study included:

(1) Nighttime light data (2000, 2007, 2012, 2018): The National Oceanic and Atmospheric Administration National Geophysical Data Center (NOAA/NGDC) website (http://www.ngdc.noaa.gov/eog/ DMSP-OLS.html) provides DMSP -OLS nighttime light datasets from 1992 to 2013 and NPP-VIIRS nighttime light data from 2012 to 2018. DMSP-OLS data eliminates the influence of clouds, fire, and other noise factors, with a gray value of 0-63, and resolution of 1 km. For this study, DMSP-OLS data were processed to the Albers and other area projections as the target projection and trimmed using the arid zone boundary in Northwest China. As the NSL data was derived from six different DMSP-OLS satellites (F10, F12, F14, F15, F16, and F18), which lacked continuity and comparability, this paper adopted the method of Wei et al (2021) to correct them. Since DMSP-OLS sensor design has limitations, this paper used the enhanced vegetation index (EVI) to reduce the saturation of DMSP-OLS. The NPP-VIIRS data are monthly data with a resolution of $430 \mathrm{~m}$. The noise factor was not removed from the NPP-VIIRS data, and the DN values of the NPP-VIIRS and DMSP-OLS data were significantly different; thus, we adopted the method of Wei et al (2021). for correction and fitting.

(2) Land use data, soil organic matter content data, soil erosion spatial distribution data, and soil type distribution data were obtained from the Data Center for Resources and Environmental Sciences, Chinese Academy of Sciences (http://www.resdc.cn), with a resolution of $1 \mathrm{~km}$. The biological abundance index was calculated by referring to the Technical Specification for Ecological and Environmental Assessment (2015).

(3) Temperature and precipitation data were derived from monthly scale data of the meteorological stations of the China Meteorological Data Network. Based on the ArcGIS10.8 software platform, the kriging interpolation method (Wei et al., 2020) was employed to perform the spatial interpolation of station data, so as to obtain spatial distribution data of the average temperature and annual precipitation in 2000, 2007, 2012, and 2018 in the arid regions of Northwest China. The resolution was 1 $\mathrm{km}$. 
(4) Digital elevation data (DEM) was derived from a geospatial data cloud platform (http://www.gscloud.cn) based on DEM

data, and referred to the relevant research results of Sheshukov et al (2018). The topographic potential index and river network density in the arid region of Northwest China were calculated with a resolution of $1 \mathrm{~km}$.

(5) Vegetation cover data $(2000,2007,2012,2018)$ were derived from the monthly scale products of NASA's EOS/MODIS dataset with a resolution of $1 \mathrm{~km}$.

(6) Social statistical data was calculated based on population distribution raster data and cultivated land and forest land raster data, with a spatial resolution of $1 \mathrm{~km}$.

\subsection{Establishment of index system}

The purpose of this study was to monitor and evaluate the ecological carrying capacity of the arid region of Northwest China. Therefore, the ecological carrying capacity was considered as the evaluation target layer, whereas the criterion layer was set as the ecological environmental elastic force (Wang et al., 2020), resource and environmental capacity (Fu et al., 2020), and socioeconomic pressure (Alpaos et al., 2021). The elastic force of the ecological environment reflects the background conditions that support the development of the natural environment and human society. In consideration of natural conditions such as the lack of water resources and sparse vegetation in the arid area of Northwest China, factors such as annual precipitation, biological abundance, topography, and soil should be judged when selecting indicators. Resource and environmental capacities primarily reflect the degree of coordination between resources, the environment, and human society. Therefore, per capita resource reserves and economic development levels were primarily considered for the selection of indicators. Social and economic pressures (i.e., pressures on resources and the environment brought about by anthropogenic development) directly reflect the challenges that exist toward socioeconomic development; thus, demographic and economic aspects were selected as indicators. Finally, this study selected 13 indicators with complete structures and easy statistics (Table 1).

\section{Table 1}

Index system of ecological vulnerability assessment

\begin{tabular}{|c|c|c|}
\hline Target layer & Criterion layer & Basic index layer \\
\hline \multirow{3}{*}{$\begin{array}{l}\text { Ecological } \\
\text { carrying capacity }\end{array}$} & Social economic pressure & Nighttime light index $(X 1)$, Land cover $(X 2)$, Population $(X 3)$ \\
\hline & Ecological environmental elastic force & $\begin{array}{l}\text { Precipitation }(X 4) \text {, Temperature }(X 5) \text {, River density }(X 6) \text {, Soil } \\
\text { erosion intensity }(X 7), \operatorname{NDVI}(X 8) \text {, Soil organic matter content }(X 9) \text {, } \\
\text { Terrain Index }(X 10) \text {, Soil types }(X 11)\end{array}$ \\
\hline & Resource and environmental capacity & Per capita arable land $(X 12)$, Per capita forest area $(X 13)$ \\
\hline
\end{tabular}

Socioeconomic pressures were the cause of state changes and the resulting responses (Haberl et al., 2009). Since the development of the west (2000), the social economy of the arid area of Northwest China developed quickly, which resulted in the rapid deterioration of the environment. The arid region of Northwest China is widely populated, where the area of urban and rural construction land accounted for only $0.52 \%$ of the total area of the study area. The spatial interpolation of statistical data cannot accurately reflect the impacts of anthropogenic activities on ecosystems. Therefore, for this paper, the nighttime light index and 
land use data were selected as indicators of the pressure of social activities on the ecological environment in the arid area of Northwest China.

The elastic force of the ecological environment reflected the long-term effects of various factors in the study area, and was the most direct reflection of the background conditions of the regional ecological environment (Kang et al. 2010). Located in the central portion of Eurasia, Northwest China is a typical arid land region with annual precipitation of less than $200 \mathrm{~mm}$, with low vegetation coverage. Therefore, this paper selected soil organic matter content data, soil erosion spatial distribution data, and soil type distribution data to characterize the soil carrying capacity factors of the study area. The average annual precipitation and annual temperature, and river network density were selected to represent the combined hydrothermal status of the study area. The normalized difference vegetation index (NDVI) reflected the biological activities in the study area and indicated the resistance of organisms to environmental change. The topographic potential index was selected as the topographic and geomorphic bearing capacity of the study area.

Resource and environment capacities are targeted measures put forward by human society to promote the sustainable development of the ecological environment. Per capita cultivated land and forested areas reflect the situation of human society with agricultural resources. Higher per capita cultivated land and forested areas can significantly improve the response capacities of humanity to ecological environment change. Consequently, per capita cultivated land and woodland areas were selected as response factors for the evaluation of the ecological carrying capacity in the arid areas of Northwest China.

\subsection{Data processing}

To verify whether there was data redundancy in the selected ecological carrying capacity evaluation index, the collinearity between independent variables was diagnosed by SPSS prior to evaluation. For this study, the variance inflation factor and tolerance were employed as elements of the multivariate collinearity diagnosis. With 10 as the boundary, the greater the variance expansibility factor was, the greater the collinearity. The tolerance value was the reciprocal of the variance expansibility factor, where the smaller the tolerance was, the stronger the collinearity, with 0.1 as the boundary. Based on the ArcGIS10.8 software platform, a $15 \mathrm{~km} \times 15 \mathrm{~km}$ fishnet was established in the arid area of Northwest China, and 9327 fish sites were generated (Table 2). Thirteen evaluation indices and ecological carrying capacity indices were extracted from these fish sites for collinearity diagnosis. The results revealed that there was no collinearity between the 13 evaluation indices in the study area, which could be used as the evaluation of the ecological carrying capacity (Table 2).

\section{Table 2}

166 Multivariate collinearity diagnosis results.

\begin{tabular}{ccc}
\hline Basic index & Tolerance & Variance inflation factor \\
\hline$X 9$ & 0.60 & 1.67 \\
$X 5$ & 0.43 & 2.30 \\
$X 6$ & 0.70 & 1.43 \\
\hline
\end{tabular}




$\begin{array}{cll}X 11 & 0.42 & 2.38 \\ X 10 & 0.35 & 2.82 \\ X 8 & 0.16 & 6.47 \\ X 7 & 0.97 & 1.03 \\ X 4 & 0.29 & 3.44 \\ X 12 & 0.76 & 1.31 \\ X 13 & 0.97 & 1.03 \\ X 2 & 0.16 & 6.24 \\ X 3 & 0.28 & 3.30 \\ X 1 & 0.19 & 5.57\end{array}$

Due to different dimensions and units, the evaluation indices were not horizontally comparable. According to the impact of each index on the ecological carrying capacity, the evaluation index was divided into a positive and negative index. The larger the negative indicator value, the smaller the ecological carrying capacity index would be, while the larger the positive indicator value, the larger the ecological carrying capacity index would be. The positive indices included the vegetation coverage index, biological richness index, average annual precipitation, river network density, per capita cultivated land area, per capita woodland area, soil organic matter content, and topographic position index. The negative indexes encompassed the annual average temperature, soil erosion intensity, and nighttime light index. The range standardization method was adopted for index standardization, and the formula was as follows (Zhang et al., 2017):

Forward indicators:

$$
R_{\mathrm{i}}=\left(X_{\mathrm{i}}-X_{\text {min }}\right) /\left(X_{\max }-X_{\text {min }}\right)
$$

Negative indicators:

$$
R_{\mathrm{i}}=\left(X_{\max }-X_{\mathrm{i}}\right) /\left(X_{\max }-X_{\min }\right)
$$

where $R_{i}$ represents the standardized value of index $i, X_{i}$ is the actual value of each index, $X_{\max }$ is the maximum value of each index, and $X_{\min }$ is the minimum value of each index.

According to the graded assignment method, the evaluation indices were graded and assigned (Li et al., 2014). According to the water conservation capacity of different land uses, various land uses were ranked in descending order: forest land, water body $<$ grassland $<$ cultivated land $<$ construction land $<$ bare land, which were assigned 0-1, respectively. According to their ecological environment protection abilities, the soil types in descending order were: chernozemic soil, black soil, black blanket soil, gray cinnamon soil < meadow soil, frozen soil, gray calcium soil, grass blanket soil, tidal soil < irrigated desert soil, gray/brown desert soil < saline soil, desert saline soil < stony soil and aeolian sand soil, with values of $0-1$, respectively.

\subsection{Spatial principal component analysis}

Based on the principle of mathematical statistics, spatial principal component analysis (SPCA) converts multiple spatial index data into a few comprehensive layers by rotating the spatial coordinate axes of feature spectrum. Because there is no 
artificial mark in the entire calculation process, the bearing capacity evaluation result is more objective. Based on the ArcGIS10.8 software platform, this study conducted spatial principal component analysis on 13 standardized indicators, which determined seven spatial principal components (Table 3) according to the principal component of more than $85 \%$, and finally calculated the

Table 3 Results of spatial principal component analysis.

\begin{tabular}{|c|c|c|c|c|c|c|c|c|c|c|c|c|}
\hline \multirow{2}{*}{$\begin{array}{l}\text { Principal } \\
\text { component }\end{array}$} & \multicolumn{4}{|c|}{ Eigenvalues } & \multicolumn{4}{|c|}{ Percent of Eigenvalues $1 \%$} & \multicolumn{4}{|c|}{ Accumulative of Eigenvalues $1 \%$} \\
\hline & 2000 & 2007 & 2012 & 2016 & 2000 & 2007 & 2012 & 2016 & 2000 & 2007 & 2012 & 2016 \\
\hline $\mathrm{P} 1$ & 0.102 & 0.100 & 0.100 & . & 37.896 & 31.749 & 35.800 & 34.312 & 0 & 31.749 & 35.800 & 34.312 \\
\hline $\mathrm{P} 2$ & 048 & 0.063 & 0.051 & 0.060 & 17.840 & 19.866 & 18.070 & 19. & 55.736 & 15 & 3.870 & 54.254 \\
\hline $\mathrm{P}$ & 34 & 0.042 & 0.036 & 0.035 & 12.556 & 13.214 & 12.920 & & 68.293 & 64.829 & 66.790 & 66.003 \\
\hline $\mathrm{P} 4$ & 0.017 & 0.025 & 0.024 & 0.024 & 6.308 & 7.955 & 8.632 & 7.920 & 74.600 & 72.784 & 75.421 & 73.923 \\
\hline P5 & 0.016 & 0.018 & 0.014 & 0.016 & 5.948 & 5.728 & 4.823 & 5.413 & 80.549 & 78.512 & 80.244 & 79.337 \\
\hline P6 & 0.012 & 0.016 & 0.013 & 0.014 & 4.390 & 5.053 & 4.576 & 4.554 & 84.938 & 83.565 & 84.820 & 83.891 \\
\hline P7 & 0.009 & 0.011 & 0.010 & 0.010 & 3.483 & 3.529 & 3.574 & 3.447 & 88.421 & 87.094 & 88.394 & 87.338 \\
\hline
\end{tabular}

$E C C_{2000}=0.3790 \times P 1+0.1784 \times P 2+0.1256 \times P 3+0.0631 \times P 4+0.0595 \times P 5+0.0439 \times P 6+0.0348 \times P 7$

$$
E C C_{2007}=0.3175 \times P 1+0.1987 \times P 2+0.1321 \times P 3+0.0795 \times P 4+0.0573 \times P 5+0.0458 \times P 6+0.0357 \times P 7
$$

$$
E C C_{2012}=0.3580 \times P 1+0.1807 \times P 2+0.1292 \times P 3+0.0863 \times P 4+0.0482 \times P 5+0.0458 \times P 6+0.0357 \times P 7
$$

$$
E C C_{2018}=0.3431 \times P 1+0.1994 \times P 2+0.11175 \times P 3+0.0792 \times P 4+0.0541 \times P 5+0.0455 \times P 6+0.0345 \times P 7
$$

$E C C_{2000}, E C C_{2007}, E C C_{2012}$, and $E C C_{2018}$ are the ecological carrying capacity indices of 2000, 2007, 2012, and 2018 respectively, and P1-P7 are the first seven principal component factors after the dimensionality reduction of the original data. The cumulative contribution rate of the first seven principal component factors was $>85 \%$, and the remaining principal component factors were found to be inconsistent with the actual ecological carrying capacity by comparison; thus, they were identified as noise and discarded.

\subsection{Standardization and classification of ecological carrying capacity}



2007, 2012, and 2018 were standardized, and the formula was:

$$
S I_{E C C}=\frac{E C C_{\mathrm{i}}-E C C_{\min }}{E C C_{\max }-E C C_{\min }}
$$

where $S I_{E C C}$ is the standardized value of the ecological carrying capacity index with a range of $0-1 ; E C C_{i}$ is the actual value of ecological carrying capacity index; $E C C_{\min }$ is the minimum value of ecological carrying capacity index; and $E C C_{\max }$ indicates the maximum value of the ecological carrying capacity index.

\subsection{Construction of ecological security pattern}

According to the ecological security pattern development method proposed by Yu Kongjian et al., the monitoring and evaluation results of the ecological carrying capacity in the arid area of Northwest China, and the regional characteristics of the region, the "origins" of the regional ecological security pattern were identified. The Minimum Cumulative Resistance (MCR) model was employed to establish the cumulative cost distance surface of the ecological source area, after which the ecological corridor and radiation channel were identified to construct the ecological security pattern using the formula (Wang et al., 2021):

$$
M C R=f_{\min } \sum_{j=n}^{i=m} D_{i j} \times R_{i}
$$

where $M C R$ is the minimum cumulative resistance value; $D_{i j}$ is the spatial distance of species from source $j$ to landscape unit $I ; R_{i}$ is the resistance coefficient of landscape unit $i$ to species movement; and $f$ is the positive correlation between minimum cumulative resistance and ecological process.

\subsubsection{Determination of ecological source area}

Ecological source areas are patches that play important roles in regional ecological environments for sustainable human development. By monitoring and evaluating the ecological carrying capacity of the study area, while identifying ecological source areas based on the special regional characteristics of the arid area in Northwest China, this study ensured their objective and comprehensive selection. Specifically, three layers of 13 indices of quantitative analysis were monitored and evaluated for their ecological carrying capacity, ecological environmental elastic force, resource and environmental capacity, and social economic pressure. Next, the ability of sustainable regional ecological development was evaluated and treated as the normalized ecological carrying capacity as the edge area. The top $20 \%$ of the plaques of all the dominant ecological areas were combined to obtain the important ecological patches, which were considered as the key development areas of pattern optimization, where the intersections of ecologically dominant areas were the ecological source areas. According to the environmental conditions of the study area, this study selected major rivers, lakes, and woodland patches larger than $10 \mathrm{~km}^{2}$ as ecological sources (Yue et al., 2012), and combined them with the ecological sources obtained through the monitoring and evaluation of ecological carrying capacities to obtain the final ecological sources. Since some small source areas have negligible impacts on the overall ecological environment, patches with areas greater than $10 \mathrm{~km}^{2}$ were selected as the ecological source areas for this study. 


\subsubsection{Development of minimum cumulative resistance surface}

To reflect the migration and movement of matter and energy between "target sources", based on the cost-distance module of the ArcGIS10.8 software platform, this investigation adopted the minimum cumulative resistance model (MCR) to calculate the cumulative cost-distance between ecological source areas and other landscape types. Subsequently, the accessibility of each landscape unit to the ecological source area was assessed. According to the ecological attributes of the study area, five factors, including landscape type, elevation, slope, normalized difference vegetation index, and soil type, were selected as resistance factors. Each evaluation index was divided into five levels, with allocated values of 1,2,3,4, and 5, respectively. The lower the value the less resistance the "source" had to overcome in the process of migration, and vice versa. The evaluation index system of the ecological source resistance surface is shown in Table 4.

Table 4 Evaluation system and values of ecological source resistance.

\begin{tabular}{|c|c|c|c|c|c|}
\hline $\begin{array}{l}\text { Ecological } \\
\text { source } \\
\text { resistance }\end{array}$ & 1 & 2 & 3 & 4 & 5 \\
\hline Elevation(m) & $>3500$ & $2500-3500$ & $2000-2500$ & $1500-2000$ & $<1500$ \\
\hline Slope $\left({ }^{\circ}\right)$ & $>40$ & $30-40$ & $20-30$ & $10-20$ & $<10$ \\
\hline $\begin{array}{l}\text { Type of } \\
\text { landscape }\end{array}$ & Waters & Forest & Grassland & $\begin{array}{l}\text { Cultivated } \\
\text { land }\end{array}$ & $\begin{array}{c}\text { Construction land, } \\
\text { unused land }\end{array}$ \\
\hline NDVI (\%) & $>70$ & $50-70$ & $30-50$ & $10-30$ & $<10$ \\
\hline Soil types & $\begin{array}{c}\text { Cold permafrost, black } \\
\text { calcium soil, grass felt soil, } \\
\text { black felt soil }\end{array}$ & $\begin{array}{l}\text { Irrigation soil, } \\
\text { meadow soil, gray } \\
\text { calcium soil }\end{array}$ & $\begin{array}{c}\text { Black earth, } \\
\text { gray-brown desert, } \\
\text { sandy soil }\end{array}$ & $\begin{array}{l}\text { Salt, } \\
\text { moisture, } \\
\text { gray brown }\end{array}$ & $\begin{array}{c}\text { Stone soil, desert } \\
\text { salt soil }\end{array}$ \\
\hline
\end{tabular}

To better analyze the minimum cumulative resistance surface, this study used the superposition analysis of production-living-ecological-land and cumulative consumption distance surface to make the ecological security pattern zoning more scientific. The grid calculator of ArcGIS10.8 software was employed to superposition the classification map of the cumulative consumption distance surface and the distribution map of production-living-ecological-land to obtain the landscape ecological function zoning map. The calculation formula was:

$$
E S P=10 \times \operatorname{Code}_{A R D}+\operatorname{Code}_{A G L}
$$

where ESP is the type code of the ecological security pattern; $\operatorname{Code}_{A R D}$ is the grade 4 cumulative cost distance surface grade code (1-4), wherein 1-4 represent the ecological conservation, optimized buffer, ecological transition, and ecological protection zones, respectively; Code $_{A G L}$ refers to four types of production-living-ecological-land type codes; and 0-3 represent unused, ecological, production and living land, respectively. In the calculated ecological security pattern type code, ten digits represent the cumulative cost distance surface classification, and one digit represents the production-living-ecological-land type (e.g., 10 represents the unused land in the ecological conservation area). 
The ecological corridor is a low cumulative resistance valley line between "sources" and an important aspect of energy circulation between two adjacent sources, which has important ecological, social, and economic functions. Based on the hydrological analysis module in the ArcGIS10.8 software platform, this study filled the depressions, calculated the flow direction and confluence accumulation based on the accumulated cost distance to the surface, and obtained the threshold values greater than 2000 through the repeated determination of the domain value. Vectorization was then performed, and the vectorized lines were smoothly processed. The minimum cost path between two sources was extracted, and the corridor between any two sources was obtained. The radiative path is the optimal path for the outward diffusion of ecological flow, and is a low resistance valley line for the outward diffusion of material with "source" as the center. Based on the accumulated cost distance surface, it will play a key role in the future development of the research area, and its own development will identify the valley lines of low resistance values radiating outward from the center of the "source".

\subsubsection{Identification of ecological nodes}

Ecological nodes are regions that connect two adjacent ecological sources in ecological space, which play a key role in the landscape ecological process. They are typically distributed in the weak ecological function of the corridor. Based on the unique physical geographical characteristics of the arid area in Northwest China, two methods were used to extract ecological nodes. The first was the intersection of the low resistance valley lines between sources, whereas the second involved 71 ecological nodes of the two types being extracted from the ridge line of ecological resistance (e.g., the intersection of the path with the maximum cumulative ecological resistance and low resistance valley line).

\section{Results and discussion}

\subsection{Overall characteristics of ecological carrying capacity}

The above indicators were calculated by the spatial main component analysis method (SPCA), whereby the values of the ecological carrying capacities of different years was obtained. Finally, the ecological carrying capacity of the northwest arid area was divided into four levels according to the natural breakpoint method (Worse ecological carrying capacity (0-0.42), Medium ecological carrying capacity (0.42-0.6), Good ecological carrying capacity (0.6-0.8), and Well ecological carrying capacity) (Fig. 2). Because the research area is in the hinterland of the Asian and European continents, it is controlled by high pressure in Asia all year round. Precipitation is scarce, vegetation coverage is low, the area of desert and Gobi exceeds $60 \%$ of the total study land area, and the ecological carrying capacity of the northwest arid area is typically weak. The Good and Well carrying areas were mainly distributed across the Altai Mountain, Tianshan Mountain, Kunlun Mountain, and Qilian Mountain areas. The Worse and Medium carrying areas were mainly distributed across the Junger Basin, Tarim Basin, and Alashan Plateau region. 

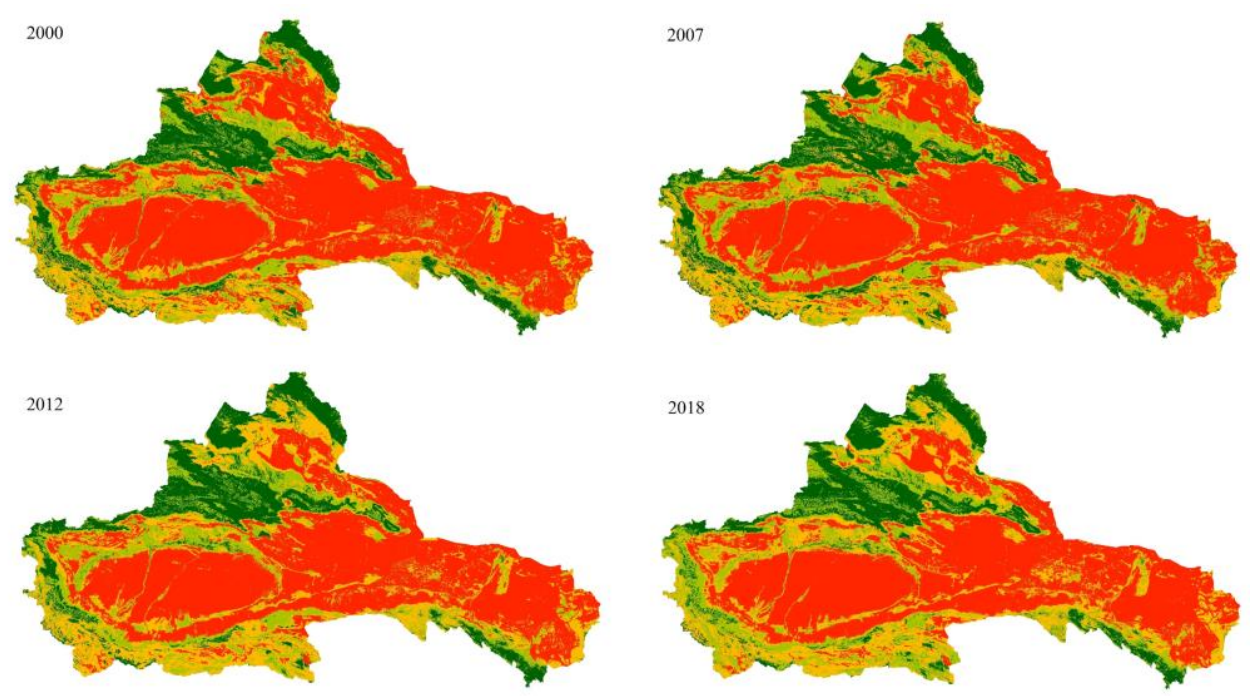

Legend Worse ecological carrying capacity

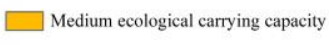

Good ecological carrying capacity

Well ecological carrying capacity

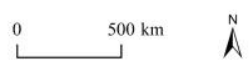

Fig.2 Ecological carrying capacity of northwest arid region from 2000 to 2018.

The basic ecological carrying capacity of the northwest arid area under study had no obvious changes. The average ecological carrying capacity decreased from 1.11 in 2000 to 1.07 in 2018, which indicated an improvement in the ecological environment in the northwest arid area (Fig. 3). From the distribution of various levels, the Well ecological carrying capacity area was basically unchanged, which was primarily due it being mainly distributed across the Altai, Tianshan, and Qilian Mountains and other high mountainous areas. These areas have higher altitudes and better ecological background conditions, and most of them are located in the ecological protection core area, which prohibited development; thus, any changes were minimal. The Good and Medium ecological carrying capacity areas are on the rise, and their share of the area increased from $34.02 \%$ in 2000 to $39.83 \%$ in 2018, which was mainly due to the improvement of the ecological environment in the northwest arid area year by year. Many Worse ecological carrying capacity areas were converted to the Medium and Good ecological carrying capacity areas. The Worse ecological carrying capacity area was rapid decline from $1080101 \mathrm{~km}^{2}$ in 2000 to $961261.6 \mathrm{~km}^{2}$ in 2018 , which was primarily related to increasing precipitation in the northwest arid area from 2000-2018, which improved the vegetation conditions and increased ecological protections.

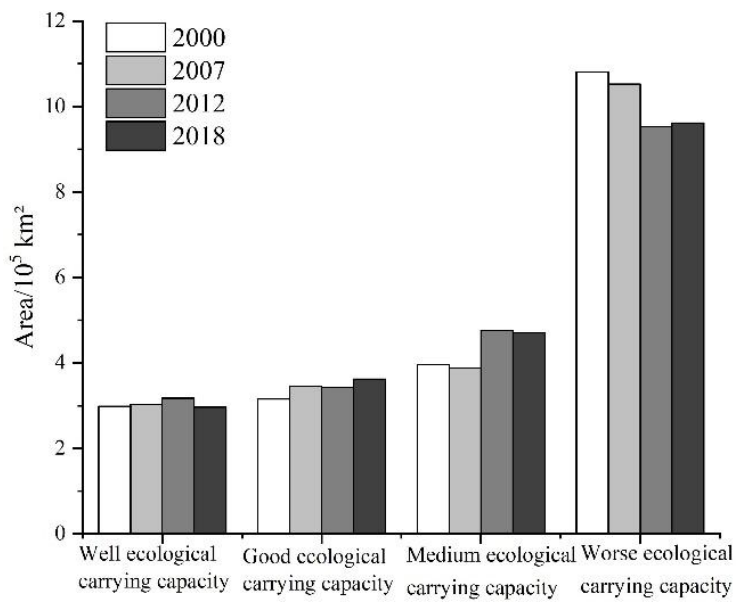

Fig. 3 Area distribution of ecological vulnerability in the northwest arid region. 
From 2000 to 2007, the ecological carrying capacity of the arid areas of Northwest China was relatively stable, where stable areas accounted for 93.87 percent of the total. The height increase and height reduction areas were sporadically scattered, and the low reduction area was slightly larger than the low increase area. Among them, the low increase area was mainly distributed across the Tianshan Mountain Range, which is primarily due to the rapid development of the social economy in the early stage of the development of the west. This involved large-scale conversion of grassland to farmland, coupled with the influences of extreme climate. The ecological carrying capacity of Tianshan area increased from a slight to mild vulnerability. From 2007 to 2012, the overall ecological carrying capacity was relatively stable, the environment continued to improve, the low ecological carrying capacity decreased by $6 \%$, and the distribution of the improved and reduction areas was concentrated.

The area of increase was mainly concentrated in the oasis area of Southern Xinjiang and the Kunlun Mountain Range, and the reduction area is mainly distributed in the northern Xinjiang region. Influenced by climate change, the glaciers in Kunlun Mountain area have melted significantly, with many glaciers degraded to bare rock. However, it still accounted for 79.69 percent of the total area in 2012-2018 although the area of the stable area was $8 \%$ lower than from 2007-2012, which was generally stable (Fig. 4). The distribution of low-level increase and height reduction areas were more dispersed, the ecological carrying capacity of Kunlun Mountain area decreased, and the ecological carrying capacity of the oasis area and Hexi corridor area of the Taklamakan Desert was on the rise, which was mainly due to the unreasonable development of primary industry, which led to continuous environmental deterioration.

Overall, the ecological environment in the northwest arid area was stable with no obvious changes and improved slightly from 2000 to 2018. Because $60 \%$ of the land in the arid areas of Northwest China is the Gobi desert, where there was far less anthropogenic interference, the stable area was the largest, whereas the height increase and height reduction areas were very small, and the sum of the two was less than $2 \%$ of the total area. The social economy of the Southern Xinjiang region has developed rapidly in recent years, particularly as relates to the development of primary industry. This has led to a reduction in its ecological background conditions coupled with the increasing population of the region, which has translated to a rapid decline in the per an increasing ecological carrying capacity. 

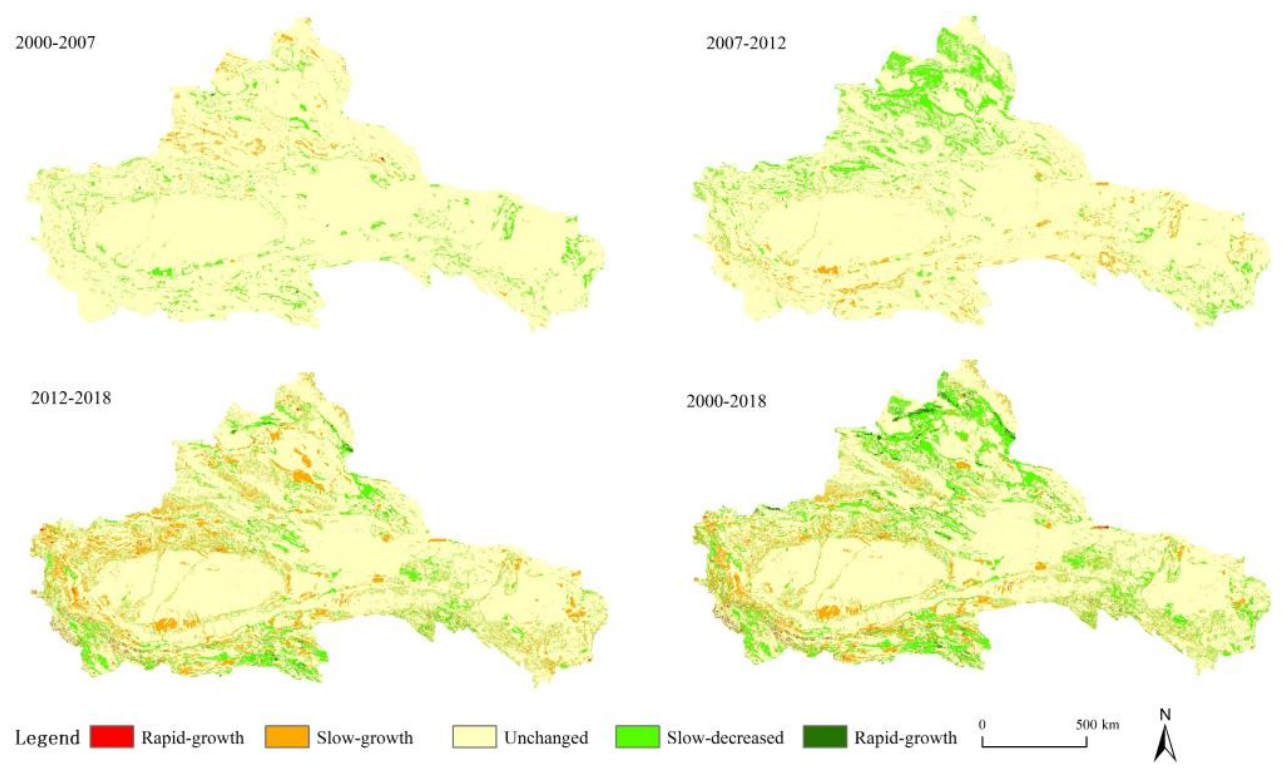

Fig. 4 Dynamic monitoring of ecological vulnerability in the northwest arid region.

\subsection{Identification and optimization of ecological security patterns}

\subsubsection{Identification and optimization of ecological source areas}

Based on the evaluation results of the ecological carrying capacity in the arid areas of Northwest China, the first $20 \%$ of the ecological carrying capacity was selected as the advantage area of ecological carrying capacity (Fig. 5a, b, c, d) to obtain the ecological sources. Overall, the ecological carrying capacity advantage areas showed a trend of increasing volatility. Consequently, the advantage areas decreased from $337,500 \mathrm{~km}^{2}$ to $255,400 \mathrm{~km}^{2}$ from $2000-2012$, with the advantage areas increasing to 355509 $\mathrm{km}^{2}$ from 2012-2018. The ecological source of the advantage areas was combined with the forest land and water (Fig. 5e) to obtain the final ecological source (Fig. 5f). The ecological source area of the northwest arid area was $237215 \mathrm{~km}^{2}$, which accounted for $\sim 11.35$ percent of the total area. Overall, the ecological source of the northwest arid area accounted for a lower proportion of the whole, which was mainly due to the larger proportion of the Gobi Desert in the northwest arid area, where the entire ecological environment was Worse. 

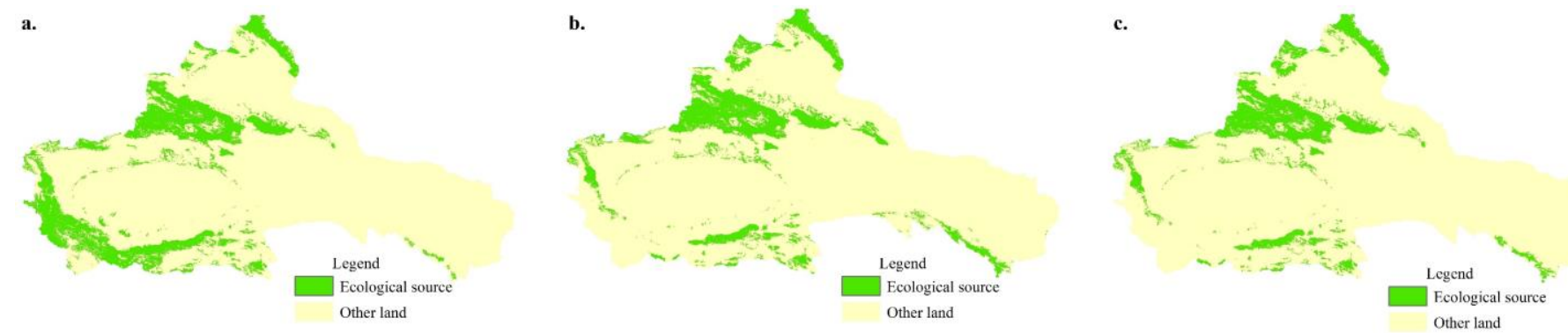

d.
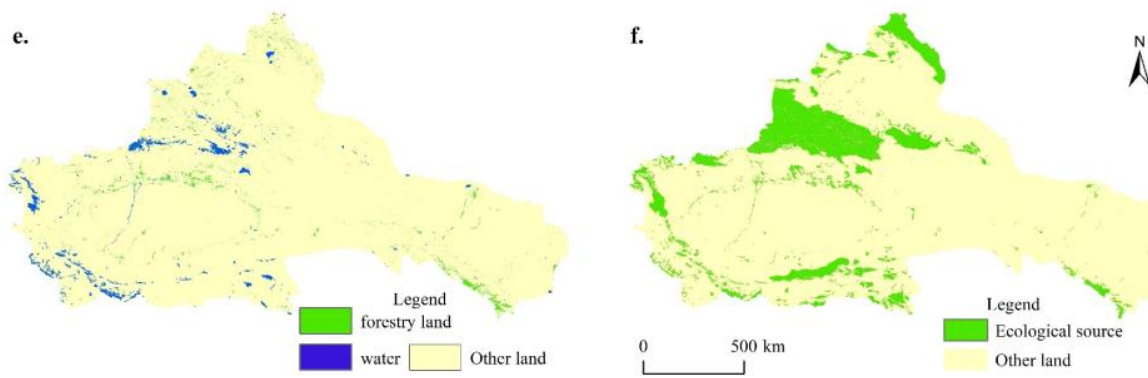

Fig.5 Ecological source of the northwest arid region. Note: a: Ecological carrying capacity advantage area in 2000; b: Ecological carrying capacity advantage area in 2007; c: Ecological carrying capacity advantage area in 2012; d: Ecological carrying capacity advantage area in 2018; e: Woodland waters greater than 10km; f: Ultimate ecological source.

Advantage ecological carrying capacity areas have an improved ecological base, where the protection and development of important ecological plaques is conducive to the continuous improvement of the area of the source plaque, which enhances the ecological function of the landscape. As shown in Fig. 6, the ecological source of the study area was distributed in the high mountain range area, and the important ecological plaques were distributed in the oasis area around the ecological source area, the Kunlun Mountain area, and the Taklamakan Desert. Relying on Altai Mountain, Tianshan Mountain, Kunlun Mountain, and Qilian Mountain in the northwest arid area, the ecologically protected areas of Altai Mountain, the Tianshan Ecological Reserve, Kunlun Mountain Ecological Reserve, and Qilian Mountain State Reserve were developed to provide ecological protection from socioeconomic development of the northwest arid area.

Judging from the changes in the ecological carrying capacities of the four stages, those of Altai and Tianshan Mountain were smaller and the ecological environment was better. The ecological carrying capacity of Kunlun Mountain area gradually decreased, whereas the ecological advantage area decreased continuously, and the ecological advantage area of Qilian Mountain area increased. Therefore, the monitoring of the glaciers in the Kunlun Mountain area should be we strengthened, and a no-go zone should be established to reduce anthropogenic interference and improve the quality of the ecological environment for the important ecological plaque areas under rapid decline. 


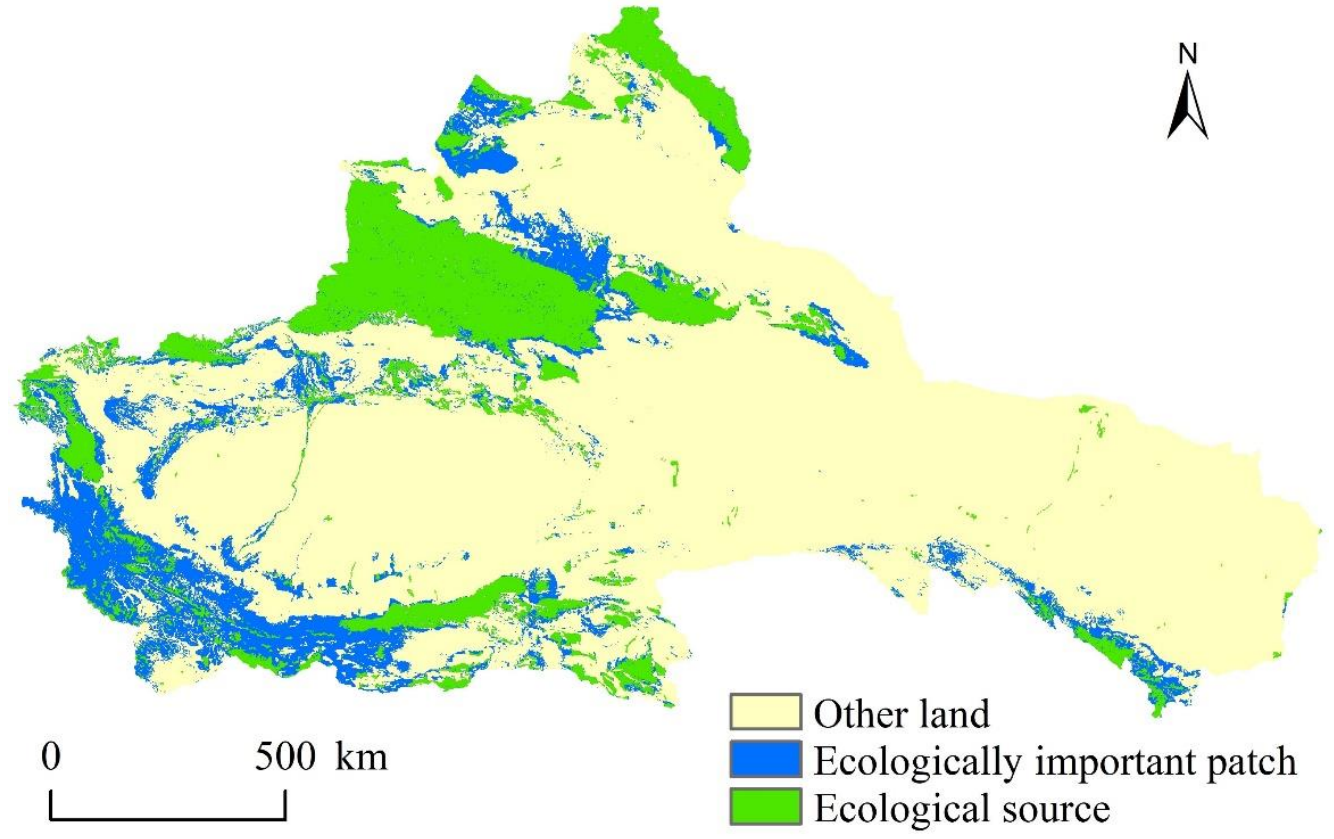

Fig.6 Map of ecological source area and important ecological patches.

\subsubsection{Landscape pattern of ecological function zoning}

As can be seen in Fig. 7, the areas with low cumulative cost were mainly distributed around alpine and water areas, while those with large cumulative consumption distances are primarily distributed in the basin and desert areas, which were further away from the water. Based on the arcGIS10.8 software platform, the study was divided into ecological conservation areas, optimized buffer zones, ecological transition zones, and ecological protection zones by the natural breakpoint method (Fig. 7). To better construct the ecological security pattern, this paper superimposed the "three-life land" with the cumulative cost distance to further analyze the ecological security pattern. "Three life" refers to the ecology, production, and living types of land use. Ecoland refers to areas that provide ecological products and services, which include mainly forest land, grassland, and water. Production land refers to functional areas that provide industry and agriculture, primarily arable land, industrial, and mining land, whereas living land refers to the functional areas that provide human habitation, leisure and recreation, mainly as urban land and rural resident land. For this paper, the land use type in 2015 was used to extract the three-life lands in the arid areas of Northwest China (Figs. $7 \mathrm{a}, \mathrm{b}, \mathrm{c})$.

The cumulative consumption distance surface and three-way land overlay pattern of the arid areas of Northwest China were calculated according Eqn. (12), (Fig. 7d). On this basis, we performed a statistical analysis of the ecological security pattern partition (Table 5). The unused area of the optimized buffer zone was mainly distributed in the high mountain range area and the oasis edge area. The ecological environment of the high mountain range area was bad, the ecological environment could be supervised, and the oasis edge area was closer to human settlement areas; thus, it was necessary to reduce human interference to prevent the oasis degradation. The results revealed that the ecological environments of the Altai Mountain, Tianshan, and QilianShan Ecological Reserves improved, and their stable development could be maintained. The unused land of ecological 
conservation areas was mainly distributed across the top of the oasis area and high mountain range; thus, the top area of Kunlun Mountain should be restored and developed from ecological land to other land types. As the unused land of the ecological conservation area of oasis area was primarily located around the ecological source, it could be enhanced with a vegetation belt to protect its development.

The unused portions of the ecological overuse area and the unused ecological protection area were in the desert hinterland, which strengthened the control of the area and prevented its erosion of the buffer zone. The ecological land of the optimizing buffer zone was mainly distributed in the grasslands of the alpine meadow and oasis areas. Since, the ecological environment of alpine meadow area is extremely fragile, a no-go zone should be established, and the livestock population should be reduced in the oasis areas to prevent grassland degradation. The eco-conservation area production, optimized buffer zone production, optimized buffer zone living, and ecological conservation area living lands were mainly distributed across the oasis area, where most were mainly cultivated lands, in addition to major cities. According to Fig. 4, the Southern Xinjiang oasis area should promote the return of farmland to grassland and the development of ecological forests in suitable areas as they had decreased significantly. The ecological environment in the northern foot of Tianshan Mountain and the Hexi area was relatively stable. Ecological transition and protection areas, ecological protection production lands, and ecological protection living spaces are typically grasslands located in the desert. This should serve to reduce the scale of human interference and development, while improving the stability of the ecological environment and maintaining the continuity of the source landscape.
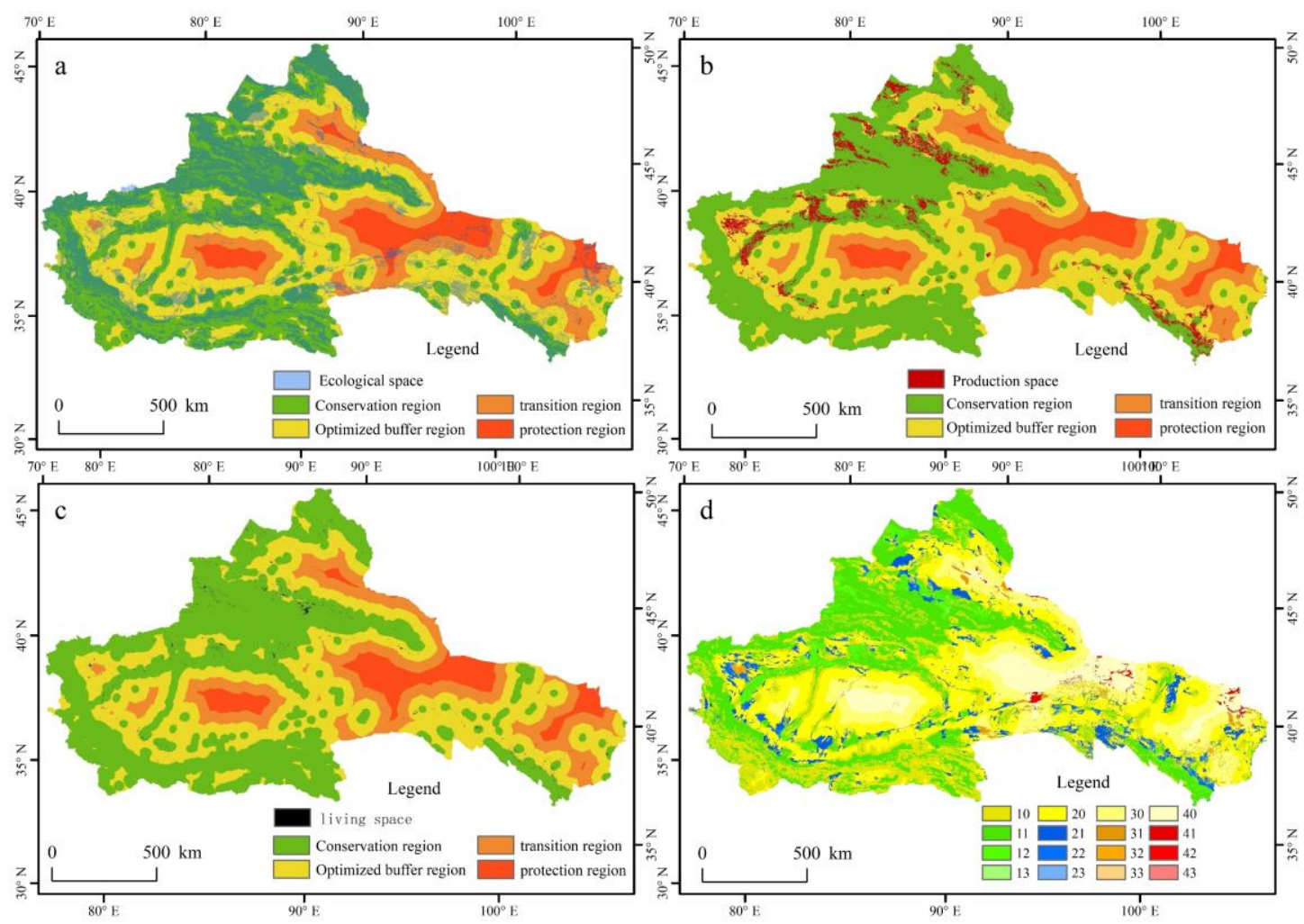

Fig.7 Different cumulative distances from the surfaces of the three-land superposition. 


\begin{tabular}{|c|c|c|c|c|}
\hline Code & Security landscape partitioning & Area $\left(\mathrm{km}^{2}\right)$ & $\begin{array}{l}\text { Percentage } \\
(\%)\end{array}$ & Main distribution area \\
\hline 20 & Optimization buffer areas unused & 568820.67 & 27.21 & Tall mountain range, oasis edge \\
\hline 11 & $\begin{array}{l}\text { ecological protection areas production } \\
\text { land }\end{array}$ & 498439.92 & 23.84 & $\begin{array}{l}\text { Altai Mountain Ecological Reserve, Tianshan } \\
\text { Ecological Reserve, Kunlun Mountain } \\
\text { Ecological Reserve, Qilian Mountain } \\
\text { Ecological Reserve }\end{array}$ \\
\hline 10 & $\begin{array}{l}\text { Ecological conservation areas unused } \\
\text { land }\end{array}$ & 348726.95 & 16.68 & Top of tall mountains, oasis area \\
\hline 30 & Ecological overuse areas underutilize & 293402.56 & 14.03 & Main desert area \\
\hline 40 & Ecological protection areas unused land & 137653.67 & 6.58 & Main desert area \\
\hline 21 & Optimize the buffer areas ecological land & 109551.53 & 5.24 & $\begin{array}{l}\text { Meadow-based, meadow belt of major } \\
\text { mountains }\end{array}$ \\
\hline 12 & $\begin{array}{l}\text { Ecological conservation areas production } \\
\text { land }\end{array}$ & 65770.21 & 3.14 & $\begin{array}{l}\text { Oasis area around Taklamakan Desert, } \\
\text { Northern Foothills of Tianshan, Hexi Region }\end{array}$ \\
\hline 22 & Optimize buffer areas production land & 26965.18 & 1.29 & $\begin{array}{l}\text { Oasis area around Taklamakan Desert, } \\
\text { Northern Foothills of Tianshan, Hexi Region }\end{array}$ \\
\hline 31 & $\begin{array}{l}\text { Ecological transition areas ecological } \\
\text { land }\end{array}$ & 22912.67 & 1.09 & $\begin{array}{l}\text { The oasis area of the desert hinterland is } \\
\text { mainly grassy }\end{array}$ \\
\hline 41 & $\begin{array}{l}\text { Ecological protection areas ecological } \\
\text { land }\end{array}$ & 9434.26 & 0.45 & $\begin{array}{l}\text { The oasis area of the desert hinterland is } \\
\text { mainly grassy }\end{array}$ \\
\hline 13 & $\begin{array}{l}\text { Ecological conservation areas land for } \\
\text { living }\end{array}$ & 4292.86 & 0.21 & $\begin{array}{l}\text { Oasis area around Taklamakan Desert, } \\
\text { Northern Foothills of Tianshan, Hexi Region }\end{array}$ \\
\hline 32 & $\begin{array}{l}\text { Ecological transition areas production } \\
\text { land }\end{array}$ & 2315.72 & 0.11 & Shiyang River Basin, Yelp River Basin \\
\hline 23 & Optimize buffer areas living space & 1609.30 & 0.07 & Optimize buffer zone production land \\
\hline 33 & Ecological transition areas living space & 77.33 & 0.01 & Shiyang River Basin, Yelp River Basin \\
\hline 42 & $\begin{array}{l}\text { ecological protection areas production } \\
\text { land }\end{array}$ & 18.81 & 0.01 & An oasis in the heart of the desert \\
\hline 43 & Ecological protection areas living space & 10.45 & 0.01 & An oasis in the heart of the desert \\
\hline
\end{tabular}

\subsubsection{Identification and optimization of ecological corridors}

As shown in Fig. 8, there were 51 ecological corridors and 949 radiation channels in the study area, with a total length of $7285.43 \mathrm{~km}$, which are mainly distributed in the western region of the study area, and less in the central and eastern regions due to the distribution of ecological sources and unique geographical environments. Because of the uneven distribution of ecological sources in the northwest arid area, the network of ecological corridors was low and not conducive to the diffusion of ecological flows. Thus, it was necessary to increase the number of corridors and improve the connectivity of ecological sources through the development of radiation channels in the structure of ecological networks. Strengthening the material circulation of existing corridors, while increasing the number of corridors are the two most important ways to optimize corridors.

The results of the optimization pattern (Fig. 8) revealed that the existing ecological corridors and radiation corridors were divided into road-type, river-type, and green corridors. Road-type corridors mainly selected G30, G7, G3014, and other 
corridor construction in the northwest arid area. The material flow between ecological plates was improved by strengthening the width of the green belts on both sides of the road. The river corridor mainly selected the Shiyang, Black, Dredging, Tarim, and Ili Rivers as its development focus. Because the river flow in the northwest arid area is small, it is necessary to limit the development of the river oasis to protect the river corridor. The green ecological corridor mainly selected the important ecological plaque and continuous oasis as the development focus, which restricted the development of the oasis area and improved the ecological environment quality of the oasis area, which then improved the organic connection between the ecological plates.

\subsubsection{Extraction and analysis of ecological nodes.}

Through the analysis of the "ridge line" and "valley line" of the cumulative cost-distance surface, a total of 71 ecological nodes were extracted. There were 15 ecological nodes distributed across the river flow area, 38 ecological nodes distributed in important ecological plaque areas such as mountains and foothills, and 18 ecological nodes located between important ecological plaques (Fig. 8) from the specific location of the distribution of ecological nodes.

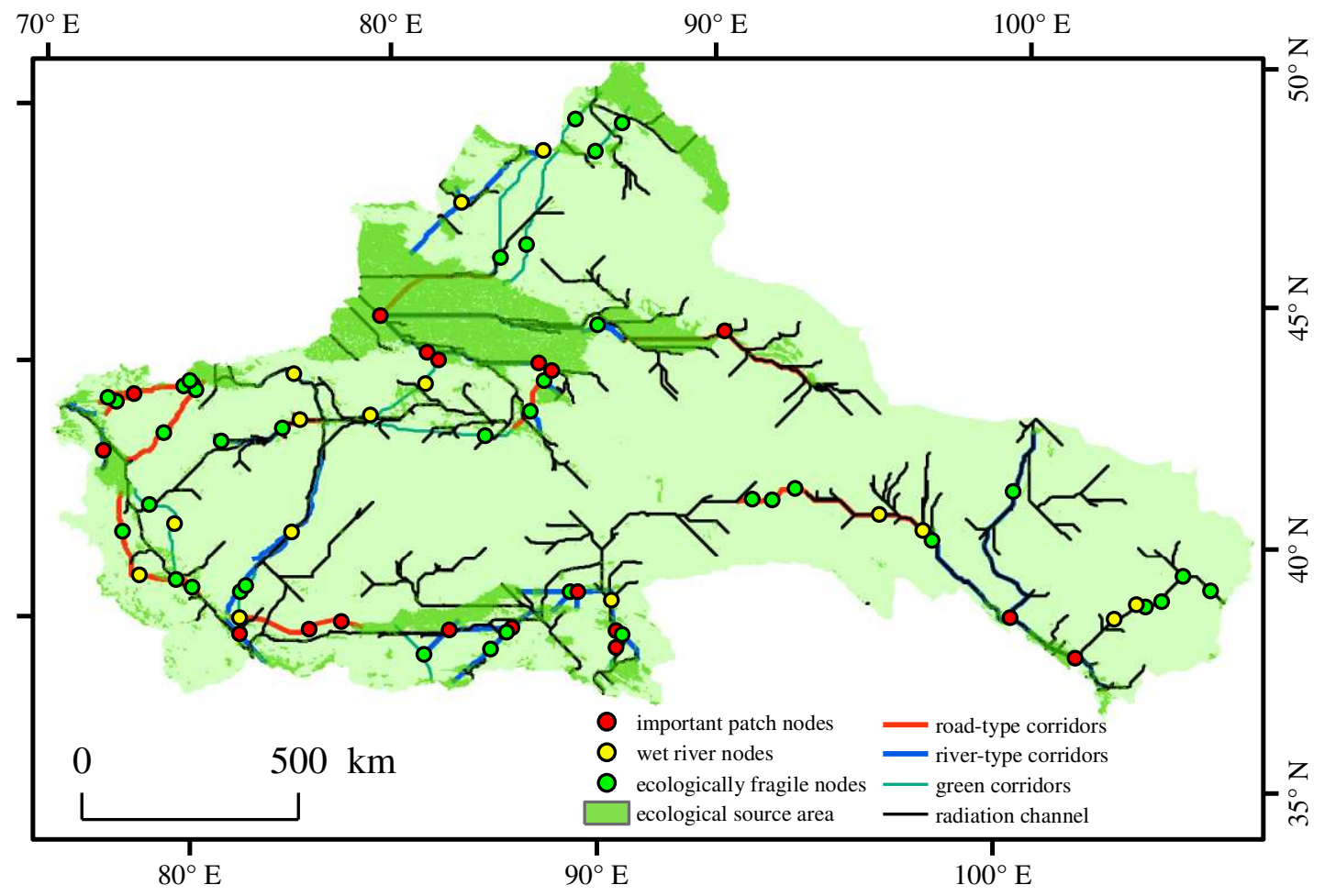

Fig.8 Optimization diagram of corridor and node patterns.

According to the concept of ecological nodes and the natural geographical characteristics of the research area, the ecological nodes of the northwest arid area were divided into three categories (important patch nodes, wet river area nodes, and ecologically fragile area nodes). Among them, the ecological fragile area nodes comprised the largest proportion and accounted for more than $50 \%$ in the ecological area. They were primarily located at the intersections between the maximum and minimum consumption paths, where the ecological environment is very fragile. They are important species migration sites; thus, no-go zones should be established to ensure the integrity of regional ecological structures and the circulation of materials. Most of the important plaque 
nodes were located at the intersections of ecological corridors, with significant material circulation. Recently, the Qilian and

Kunlun Mountain areas were greatly impacted by human activities; thus, the degree of landscape fragmentation has increased.

Therefore, it is necessary to reduce anthropogenic interference in protected areas to maintain the stability of important ecological plaques. Water resources are critical for the restriction of biological activities in the northwest arid area, and rivers are very important to the development of the ecological environment. The rivers in the northwest arid area are mainly inland, and the flow rates are relatively small. Many rivers flow through the desert and other areas where the ambient environment is harsh; thus, the development of nodes in the wet river areas should be reduced when optimizing patterns to maintain their overall ecological integrity.

\section{Conclusion}

From the development of the western region in 2000 to the popularization of the theory of "two mountains", increasing attention has been paid to the protection of ecosystems in the arid area of Northwest China. With this background, our study employed the spatial main component analysis method (SPCA) to systematically monitor and evaluate the ecological carrying capacity of the arid regions of Northwest China toward the development of sustainable ecological security patterns. The following conclusions were obtained:

(1) On the whole, the ecological carrying capacity of the northwest arid region was weak, with the ecological carrying capacity increasing from east to west. The Good and Well ecological carrying capacity areas were primarily distributed across the Altai, Tianshan, Kunlun, and Qilian Mountains, and other regions. The Weak and Medium ecological carrying capacity areas were primarily distributed across the Junger Basin, Tarim Basin, and Alashan Plateau.

(2) From changes in the spatiotemporal characteristics of the ecological carrying capacity, the Weak carrying capacity of these areas decreased, while the Well carrying capacity was increasing. The Hexi region, Northern Xinjiang region, and Western Inner Mongolia showed a general upward trend, while the southern Xinjiang portion showed a downward trend. The Bayingolin Mongol Autonomous Prefecture, Yili Kazak Autonomous Prefecture, Altay City, and Hami City, for the most part, remained unchanged. Overall, the ecological carrying capacities of the northwest arid areas increased slightly but steadily

(3) Based on the results of the monitoring and assessment of the ecological carrying capacities, as well as the unique geographical characteristics of arid areas of Northwest China, the ecological source area was extracted as $237215 \mathrm{~km}^{2}$, which accounted for 11.35 per cent of the total study area. Generally, the ecological source area accounted for a low proportion of the whole and the distribution of the ecological source areas was uneven. The ecological sources of the north area were higher than the south, and those of the west were higher than the east. From the topographical perspective, the ecological source areas were mainly distributed across the high mountain range area, with the basin areas having fewer than the mountainous regions.

(4) Based on the MCR model and land use data, the arid areas of Northwest China were divided into 16 ecological safety pattern partitions, and three types of corridors, such as road, river, and green corridors were extracted. Further, three types of 
important plaque nodes were identified, such as river wet area nodes, and ecological fragile area nodes, and then optimized in combination with the ecological carrying capacity monitoring and evaluation results.

However, ecological carrying capacities are complex systems. The comprehensiveness and scientific nature of the selected indicators directly determined the accuracy of the results in the evaluation of ecological carrying capacities. Thus, the ecological carrying capacities were evaluated using spatial principal component analysis (SPCA) from 17 indicators with three criteria levels, which took into account characteristics of the natural environment such as hydrology, soil, and vegetation, and the social environment such as urban, population, and economy. However, the data collection was confronted with great challenges due to the extensive scope, large areas, and significant regional differences, particularly in terms of the accuracy of the spatial rastering of statistics. Therefore, future research work should further study and perfect the aspects of index refinement and data spatialization. However, in terms of the macro-guidance of ecological management and ecological pattern optimization, this study provides new perspectives in the aspects of ideas and methods, which are worthy of attention as references in the future.

\section{Availability of data and materials}

The data presented in this study are available from the corresponding author on reasonable request.

\section{Author contribution}

Xiaoyan Cao: Writing - original draft, Writing - review \& editing, Software Visualization. Validation. Jizong Jiao:

Funding acquisition, Methodology, Project administra- tion, Supervision. Xiaoyan Cao: Software Visualization.

Investigation. Xiuli Liu: Software Visualization. Investigation. Wanyang Zhu: Investigation. Haoran Wang: Visualization,

482 Investigation.

\section{Funding}

The research was funded by the National Key Research and Development Program of China (Grant No.:

2018YFC1903700). The Fundamental Research Funds for the Central Universities (Grant No.: lzujbky-2020-71).

\section{Declarations}

Ethics approval and consent to participate: Not applicable

\section{Consent for publication: Not applicable}

Competing interests: The authors declare that they have no competing interests 


\section{References}

Banos-González I, Martínez-Fernández J, Esteve-Selma MÁ (2015) Dynamic integration of sustainability indicators in insular socio-ecological systems. Ecological Modelling 306: 130-144. doi:10.1016/j.ecolmodel.2014.08.014.

Ch R, Martin D.A, Vargas JF (2021) Measuring the size and growth of cities using nighttime light. Journal of Urban Economics 125: 103254. doi:10.1016/j.jue.2020.103254.

Chen Y, Tian W, Zhou Q, Sh T (2021) Spatiotemporal and driving forces of Ecological Carrying Capacity for high-quality development of 286 cities in China. Journal of Cleaner Production 293: 126186. doi:10.1016/j.jclepro.2021.126186.

Dallas M D, Kerzee RG, Bing-Canar J, Mensah EK, Oroke KG, Swager R R (1996) An Indicator of Solid Waste Generation Potential for Illinois Using Principal Components Analysis and Geographic Information Systems. J Air Waste Manag Assoc 46: 414-421. doi:10.1080/10473289.1996.10467474.

D'Alpaos C, D'Alpaos A (2021) The Valuation of Ecosystem Services in the Venice Lagoon: A Multicriteria Approach. Sustainability 13: 9485. doi:10.3390/su13179485.

Feng Z, Peng J, Wu J (2020) Using DMSP/OLS nighttime light data and K-means method to identify urban-rural fringe of megacities. Habitat International 103:102227. doi:10.1016/j.habitatint.2020.102227.

Filgueira R, Guyondet T, Thupaki P, Sakamaki T, Grant J (2021) The effect of embayment complexity on ecological carrying capacity estimations in bivalve aquaculture sites. Journal of Cleaner Production 288: 125739. doi:10.1016/j.jclepro.2020.125739.

Fu J, Zang C, Zhang J (2020) Economic and resource and environmental carrying capacity trade-off analysis in the Haihe River basin in China. Journal of Cleaner Production 270: 122271. doi:10.1016/j.jclepro.2020.122271.

Fuju X I E, Mingxi Z, Hong Z (2011) Research on Ecological Environmental Carrying Capacity in Yellow River Delta. Energy Procedia 5: 1784-1790. doi:10.1016/j.egypro.2011.03.304.

Haberl H, Gaube V, Díaz-Delgado R, Krauze K, Neuner A, Peterseil J, Plutzar C, Singh SJ, Vadineanu A (2009) Towards an integrated model of socioeconomic biodiversity drivers, pressures and impacts. A feasibility study based on three European long-term socio-ecological research platforms. Ecological Economics 68: 1797-1812. doi:10.1016/j.ecolecon.2008.11.013.

Jin X, Li X, Feng Z, Wu J, Wu K (2020) Linking ecological efficiency and the economic agglomeration of China based on the ecological footprint and nighttime light data. Ecological Indicators 111: 106035. doi:10.1016/j.ecolind.2019.106035.

Kang, P.; Xu, L. The urban ecological regulation based on ecological carrying capacity. Procedia Environmental Sciences, 2010, 2, 1692-1700. doi:10.1016/j.proenv.2010.10.180.

Li D, Xu E, Zhang, H (2020) Influence of ecological land change on wind erosion prevention service in arid area of northwest China from 1990 to 2015. Ecological Indicators 117: 106686. doi:10.1016/j.ecolind.2020.106686.

Li F, Ye Y, Song B, Wang R (2015) Evaluation of urban suitable ecological land based on the minimum cumulative resistance model: A case study from Changzhou, China. Ecological Modelling 318: 194-203. doi:10.1016/j.ecolmodel.2014.09.002.

Li P, Zhang R, Xu L (2021) Three-dimensional ecological footprint based on ecosystem service value and their drivers: A case study of Urumqi. Ecological Indicators 131: 108117. doi:10.1016/j.ecolind.2021.108117.

Li W, Yi P, Zhang D, Zhou Y (2020) Assessment of coordinated development between social economy and ecological environment: Case study of resource-based cities in Northeastern China. Sustainable Cities and Society 59: 102208 doi:10.1016/j.scs.2020.102208.

Li Y, Zhou G.Z.J (2011) Establishment of Evaluation Index System of Ecological Carrying Capacity in Changping District Pusalu Village. Procedia Environmental Sciences 11: 899-905. doi:10.1016/j.proenv.2011.12.138.

Peng J, Du Y, Liu Y, Hu X (2015) How to assess urban development potential in mountain areas? An approach of ecological carrying capacity in the view of coupled human and natural systems. Ecological Indicators 60: 1017-1030. doi:10.1016/j.ecolind.2015.09.008.

Sheshukov A.Y, Sekaluvu L (2018) Hutchinson, S.L. Accuracy of topographic index models at identifying ephemeral gully trajectories on agricultural fields. Geomorphology 306: 224-234. doi:10.1016/j.geomorph.2018.01.026. 
Sun J, Zuo H, Wang W, Pecht M.G. (2011) Application of a state space modeling technique to system prognostics based on a health index for condition-based maintenance. Mechanical Systems and Signal Processing 28: 585-596. doi:10.1016/j.ymssp.2011.09.029.

Tan M, Li X, Li S, Xin L, Wang X, Li Q, Li W, Li Y, Xiang W (2017) Modeling population density based on nighttime light images and land use data in China. Applied Geography 90: 239-247. doi:10.1016/j.apgeog.2017.12.012.

Wang Y, Chen X (2020) Natural resource endowment and ecological efficiency in China: Revisiting resource curse in the context of ecological efficiency. Resources Policy 66: 101610. doi:10.1016/j.resourpol.2020.101610.

Wang Z, Shi P, Zhang X, Tong H, Zhang W, Liu Y (2021) Research on Landscape Pattern Construction and Ecological Restoration of Jiuquan City Based on Ecological Security Evaluation. Sustainability 13: 5732. doi:10.3390/su13105732.

Wei W, Guo Z, Xie B, Zhou J, Li C (2020) Quantitative simulation of socio-economic effects in mainland China from 1980 to 2015: A perspective of environmental interference. Journal of Cleaner Production 253: 119939. doi:10.1016/j.jclepro.2019.119939.

Wei W, Guo Z, Zhou L, Xie B, Zhou J (2020) Assessing environmental interference in northern China using a spatial distance model: From the perspective of geographic detection. Sci Total Environ 709: 136170. doi:10.1016/j.scitotenv.2019.136170.

Wei W, Shi S, Zhang X, Zhou L, Xie B, Zhou J, Li C (2019) Regional-scale assessment of environmental vulnerability in an arid inland basin. Ecological Indicators 109: 105792. doi:10.1016/j.ecolind.2019.105792.

Wei W, Zhang X, Cao X, Zhou L, Xie B, Zhou J, Li C (2021) Spatiotemporal dynamics of energy-related CO $\mathrm{CO}_{2}$ emissions in China based on nighttime imagery and land use data. Ecological Indicators 131: 108132. doi:10.1016/j.ecolind.2021.108132.

Wei W, Zhang X, Zhou L, Xie B, Zhou J, Li C (2021) How does spatiotemporal variations and impact factors in $\mathrm{CO}_{2}$ emissions differ across cities in China? Investigation on grid scale and geographic detection method. Journal of Cleaner Production 321: 128933. doi:10.1016/j.jclepro.2021.128933.

Wei X, Shen L, Liu Z, Luo L, Wang J (2020) Chen Y. Comparative analysis on the evolution of ecological carrying capacity between provinces during urbanization process in China. Ecological Indicators 112 : 106179. doi:10.1016/j.ecolind.2020.106179.

Wu T, Sang S, Wang S, Yang Y, Li M (2020) Remote sensing assessment and spatiotemporal variations analysis of ecological carrying capacity in the Aral Sea Basin. Sci Total Environ 735: 139562. doi:10.1016/j.scitotenv.2020.139562.

Wu X, Hu F (2020) Analysis of ecological carrying capacity using a fuzzy comprehensive evaluation method. Ecological Indicators 113: 106243. doi:10.1016/j.ecolind.2020.106243.

Yue D (2012) RS \& GIS-based Spatial Analysis on Ecological Carrying Capacity Pattern of Northwest China: Does Supply Meet Demand? Quaternary International 16: 279-280. doi:10.1016/j.quaint.2012.08.1945.

Zhang M, Liu Y, Wu J, Wang T (2018) Index system of urban resource and environment carrying capacity based on ecological civilization. Environmental Impact Assessment Review 68: 90-97. doi:10.1016/j.eiar.2017.11.002.

Zheng Z, Wu Z, Chen Y, Guo G, Cao Z, Yang Z, Marinello F (2021) Africa's protected areas are brightening at night: A long-term light pollution monitor based on nighttime light imagery. Global Environmental Change 69: 102318. doi:10.1016/j.gloenvcha.2021.102318. 